\title{
PEDAGOGIA HISTÓRICO-CRÍTICA: UMA PROPOSTA DIDÁTICA PARA AUXILIAR O DOCENTE NA CONSTRUÇAO DO SENSO CRÍTICO DOS EDUCANDOS
}

\author{
Kátia Rodrigues Montalvão Paias \\ Serviço Nacional de Aprendizagem Comercial -SENAC, Maringa, PR. E-mail: katiapaias@gmail.com.
}

\begin{abstract}
RESUMO
Este artigo faz uma abordagem teórica conceitual acerca da educação na sociedade líquida, abordando as características e os desafios que o campo educacional enfrenta na sociedade contemporânea. A educação tem que superar as dificuldades da atual sociedade e para isso acontecer, é necessário que docente saiba a importância de sua prática, visto que a mesma poderá desenvolver nos educando a consciência crítica capaz de questionar o impacto das experiências presentes no cotidiano, além de saber enfrentá-las e por fim desafiar as pressões que surgem na sociedade. Portanto, este artigo tem como objetivo apresentar a pedagogia histórico critica como uma metodologia capaz de auxiliar a prática docente no processo de ensino e aprendizagem, porque ela proporciona um diálogo aberto entre o docente e os alunos capaz de promover uma mudança de conduta em ambos. A pesquisa indica que a pedagogia HistóricoCrítica pode ser utilizada como uma metodologia capaz de promover o senso crítico nos alunos e de promover uma mudança de conduta nos educandos para combater a liquidez desta sociedade. Palavras-chave: Sociedade líquida. Educação. Pedagogia Histórico- Crítica. Crítica. Docente.
\end{abstract}

\section{PEDAGOGY HISTORICAL-CRITICAL: A TEACHING PROPOSAL TO ASSIST THE TEACHER IN CONSTRUCTION OF THE CRITICAL SENSE OF STUDENTS}

\begin{abstract}
This article makes a conceptual theoretical approach about education in the net society, addressing the characteristics and challenges that the educational field faces in contemporary society. Education has to overcome the difficulties of the current society and for this to happen, it is necessary for teachers to know the importance of their practice, since it can develop in educating us the critical awareness capable of questioning the impact of the experiences present in the daily life, besides know how to face them and ultimately challenge the pressures that arise in society. Therefore, this article aims to present historical - critical pedagogy as a methodology capable of assisting teaching practice in the teaching and learning process, because it provides an open dialogue between the teacher and the students capable of promoting a change of conduct in both. The research indicates that the Historical-Critical pedagogy can be used as a methodology capable of promoting the critical sense in the students and of promoting a change of conduct in the students to combat the liquidity of this society.
\end{abstract}

Keywords: Liquid society. Education. Historical-Critical Pedagogy. Critical. Teacher. 


\section{INTRODUÇÃO}

A sociedade contemporânea é denominada como a sociedade líquida, a qual é marcada pela individualidade, competição, instantaneidade e pela incapacidade dos indivíduos de criticarem a liberdade ilusória. A liberdade ilusória é a responsabilização do indivíduo pelo seu sucesso ou fracasso, e ausência do Estado em relação ao desemprego, educação, moradia entre outras tragédias sociais.

A educação também sofre influência desta sociedade, visto que ela atende as exigências do mercado, preparando os alunos para aprenderem conhecimentos que serão necessários por um tempo de sua vida, e logo depois, substituídos por novos conhecimentos, visto que as mudanças tecnológicas fazem os conhecimentos tornarem-se obsoletos rapidamente. A educação nesta sociedade perdeu o seu o valor pragmático da antiga sabedoria, e as pessoas que articulam a aprendizagem tiveram que redirecionar o seu foco de pesquisa, já que as pesquisas são perecíveis e perdem a importância rapidamente.

Neste Contexto, o desafio da educação nesta sociedade é o desenvolver a criticidade nos alunos, a qual deve ser capaz de questionar a liberdade ilusória, que coloca toda a responsabilidade no indivíduo. Portanto, este artigo tem como objetivo apresentar a pedagogia histórico - critica como uma metodologia capaz de auxiliar a prática docente no processo de ensino e aprendizagem e desenvolver a consciência crítica nos educando. $E$, responder à problemática: como que a pedagogia histórico-crítica pode auxiliar o docente a promover o senso crítico nos alunos? O professor pode utilizá-la para verificar os percalços e problemas que os acadêmicos vivenciam, para que ambos busquem os conhecimentos científicos e possíveis soluções para a superação desta sociedade liquefeita.

\section{METODOLOGIA}

A presente pesquisa é uma revisão teórico-conceitual sobre o papel da Educação na Sociedade Líquida e apresenta a pedagogia histórico crítica como uma ferramenta capaz de auxiliar o docente no processo de ensino e aprendizagem e na construção do senso crítico dos educando. Com o intuito de alcançar os objetivos deste artigo, foi realizada uma pesquisa de natureza bibliográfica, a qual tem como finalidade explicar problemas com embasamento em conceitos, dados e informações coletadas de livros, de revistas, documentos entre outros materiais, os quais podem ser de diversos escritores que sejam especialistas do tema discutido (REIS, 2008).

\section{RESULTADOS E DISCUSSÕES EDUCAÇÃO NA SOCIEDADE LÍQUIDA}

Segundo o pesquisador Bauman (2001), a sociedade contemporânea é classificada como a "sociedade da modernidade fluida", é uma sociedade inóspita para a crítica, os relacionamentos, consumo e negociações não possuem a função de durabilidade, ou seja, eles não duram eternamente. A característica desta sociedade é que tudo tem "curto prazo", substituído o "longo prazo", sendo a geração instantânea, onde tudo deve ser para agora, imediato, é incapaz de questionar a administração de qualquer estabelecimento.

A modernização e a sede de destruição criativa são encarregadas por estimular a produtividade e a competitividade de modo desenfreado, a ponto de:

[...] a compulsiva e obsessiva, continua, irrefreável e sempre incompleta modernização; a opressiva e inerradicável, insaciável sede de destruição criativa (ou de criatividade destrutiva, se for o caso: de "limpar o lugar" em nome de um "novo e aperfeiçoado" projeto; de "desmantelar" "cortar" "defasar" "reunir" ou "reduzir' tudo isso em nome da maior capacidade de 
fazer o mesmo no futuro - em nome da produtividade ou da competitividade".) (BAUMAN, 2001, p.37).

Para Bauman (2001), as consequências da produtividade e da competitividade fazem com que as pessoas sintam a liberdade ilusória, a qual é produto do processo de individualização. Esta liberdade ilusória coloca a responsabilidade nos indivíduos pela autoconstrução de sua própria vida, onde ele passa ser o responsável pelo seu sucesso ou fracasso, responsabilizando-o pelas suas próprias desgraças, desemprego, drogas, o não ingresse na faculdade, miséria, depressão entre outras tragédias. Eles são "libertos" de tal maneira que não possuem nenhuma garantia social, onde o Estado se ausenta de qualquer responsabilidade, sucateando as entidades sociais e depois as privatizando.

O pesquisador afirma que a finalidade da crítica diante dessa sociedade líquida deve ser focada na desconstrução dessa liberdade ilusória, visto que conforme o sistema capitalista avança na conquista dos espaços planetários, desaparece a ideia de comunidade, a qual existe a partilha das vantagens entre os membros, e emerge a ideia de que as pessoas merecem o que conseguem obter por seus próprios meios e músculos, aumentando a desigualdade (BAUMAN, 2001).

O propósito da crítica somente será alcançado se existir meios para o desenvolvimento deste senso crítico nos indivíduos. Neste contexto, a educação tem um papel fundamental, visto que ela pode ser uma ferramenta capaz de desenvolver a criticidade nos indivíduos. Mas, qual é o contexto da educação nesta sociedade? Quais as dificuldades que o cenário educativo enfrenta?

A educação sofre influências desta sociedade, ela atende as exigências do mercado, perde o seu o valor pragmático da antiga sabedoria, e as pessoas que articulam a aprendizagem, redirecionaram o seu foco de atenção. Por exemplo, um estudioso da educação não consegue desenvolver um estudo linear, sobre um determinado tema ou objeto de estudo por muitos anos, ou seja, nesta sociedade, é quase impossível manter o mesmo foco e a mesma validade de estudo por trinta anos, já que a educação tornou-se perecível. Portanto, a educação na sociedade líquida, também se tornou liquefeita, já que os docentes tem que desenvolver nos educando o talento de aprender rápido e a capacidade de esquecer imediatamente o que foi aprendido, com o lema de que nesta sociedade, tem que aprender a aprender (BAUMAN, 2010).

Segundo Bauman (2010), a ausência de certezas abrange todas as áreas do conhecimento, inclusive o campo da educação, visto que as informações ficam obsoletas rapidamente e o conhecimento torna-se descartável. E, o sucesso é saber o momento certo de esquecer o conhecimento adquirido e substituí-lo por um novo conhecimento imposto pela sociedade tecnológica, já que os indivíduos não almejam o acúmulo de conhecimento, mas o prazer passageiro que ele proporciona.

Diante deste cenário, a educação está fragilizada, visto que o mundo além dos muros da escola mudou e é preciso aprender a viver nesta sociedade, já que "a arte de viver num mundo hipersaturado de informação ainda não foi apreendida. E o mesmo vale também para a arte ainda mais difícil de preparar os homens para esse tipo de vida" (BAUMAN, 2010, p. 60). Deste modo, a educação e a aprendizagem para ter utilidade nesta sociedade, devem ser contínuas de modo que dure toda a vida, ou seja, tem como objetivo fazer com que este mundo que se encontra constantemente em mudança seja mais hospitaleiro para a humanidade (BAUMAN, 2009).

Para promover uma educação e uma aprendizagem que tenha utilidade para avida toda, é essencial que o "mundo da vida" do educando seja vinculado ao "mundo da escola", o professor deve ultrapassar as barreiras físicas e trazer a realidade do educando para dentro das salas de aulas, promovendo a humanização, a formação pessoal e de grupo. Neste mundo saturado de informações, necessariamente, o docente tem que construir nos educando a consciência crítica e deve ter a ciência de que a educação vai além dos muros das escolas, ela está presente nas mídias, na política, nas lutas dos movimentos sociais, na comunidade, nas reuniões dos bairros, nas 
reuniões do posto de saúde, nas reuniões das escolas, nas reuniões de todas as entidades presentes na comunidade (BAUMAN, 2010).

Segundo Dowbor (1996), não é possível ignorar as tecnologias, já que a informática revolucionou todas as áreas, principalmente, as que lidam com o conhecimento, as telecomunicações e a telemática (associação da informática com as telecomunicações). Assim, os docentes com o objetivo de promover uma educação significativa, têm um importante desafio pela frente, o de metodologicamente ser o mediador entre o acadêmico e as novas tecnologias, mas principalmente, o de ensinar lhes o "verdadeiro valor" das relações, visto que "a utilização da tecnologia pela tecnologia não tem sentido de ser e acaba por não gerar a construção e a aquisição do conhecimento, não oportunizando o pensamento crítico" (BERTONCELLO, 2011, p.16).

O Professor deve compreender que a finalidade da educação nesta sociedade é a de desenvolver nos educando a capacidade de questionar o impacto das experiências presentes no cotidiano, além de saber enfrentá-las e por fim desafiar as pressões que surgem na sociedade (BAUMAN, 2009).

Em meio a esta sociedade líquida e às tecnologias, o papel do docente inevitavelmente tem que ser redirecionado, ou seja, "o seu papel é fundamentalmente o de um orientador/mediador (MORAN, 2012, p.30)". Portanto, este precisa ter ciência que não é mais o detentor do saber e deve tornar-se o mediador dos sentimentos, conhecimentos e informações, com o objetivo de gerar nos educando a criticidade.

Por exemplo, um aluno tem um iPhone 7 e durante o dia acessa todas as notícias que foram divulgadas, ao chegar na sala de aula, ele sabe de todos os acontecimentos econômicos, políticos, culturais e de entretenimento de seu país e de sua cidade, por isso, ele não está interessado em receber novas informações e consequentemente, se o professor passar mais informações, ele ficará tediado.

Para os pesquisadores Albuquerque e Dal, (2014, p. 102), esta sociedade é "[...] uma sociedade baseada na produção de valores informacionais, e não valores materiais. Sua principal força é a informação produzida e distribuída em redes, ao alcance de todos". Como as informações são distribuídas em redes, o professor não deve concorrer com elas, já que as redes promovem o processo de informação demasiadamente. As redes emitem aos leitores, telespectadores ou ouvintes, um conjunto de dados codificados (informações) e estes são entendidos e assimilados por eles (MATOS, 2009).

No entanto, o pesquisador Libâneo (2013), afirma que a prática de transmitir conhecimentos e de sobrecarregar os acadêmicos de conteúdos repetitivos e decorados, ainda está presente nas salas de aulas, fazendo com que o ensino tenha a tarefa de mera transmissão de informações. Esta prática está ligada a pedagogia tradicional que tinha como objetivo transmitir a cultural geral para todos os alunos, de modo que estes somente ouvissem, sem se quer questionar ou dialogar. Transmitir a cultura geral não é suficiente para esta sociedade "liquefeita" "fluida" intitulada pelo pesquisador Bauman (2001), até porque, segundo Albuquerque e Dal, (2014), as informações estão presentes nas redes de comunicação de modo rápido e versátil.

Neste contexto, é oportuno questionar: como que a pedagogia histórico-crítica pode auxiliar o docente a promover o senso crítico nos alunos? Já que a visão da educação atualmente está fundamentada na ideia de que ela é um produto perecível, diferentemente do que era pregado na sociedade sólida, que via a educação como algo duradouro (BAUMAN, 2010).

PEDAGOGIA HISTÓRICO-CRÍTICA: FERRAMENTA PARA A SUPERAÇÃO DA EDUCAÇÃO LIQUEFEITA

Uma proposta para responder os questionamentos levantados neste artigo, é a pedagogia Histórico-Crítica como didática, na qual o professor João Luiz Gasprin oferece algumas 
alternativas, as quais são: a prática Social Inicial do conteúdo, a problematização, a instrumentalização, a catarse e a prática Social Final.

A Prática Social Inicial do Conteúdo é a primeira fase, neste momento o professor mobilizará o acadêmico para que construa o seu próprio conhecimento escolar. Sugere-se que o professor proponha a sala de aula um primeiro contato com o conteúdo que será estudado. A leitura sobre um texto, uma reportagem ou uma notícia sobre o assunto da aula é uma proposta pedagógica para este momento, com esta ação, o professor conduzirá o aluno à mobilização, ou seja, a um momento de despertamento.

Outros exemplos de atividades que podem ser desenvolvida neste momento é propor ao aluno "[...] estudar e pesquisar de modo independente e o aprendizado colaborativo, dinamizando a comunicação e a troca (PATRONI et al., 2009, p.45)". Ao estimular o aluno a pesquisar, o ensino não estará centrado somente no professor, e a pesquisa propiciará novos conhecimentos, e o hábito de selecionar as fontes seguras, além de permitir a interação entre os membros de uma sala, compartilhando a novidade, de modo que a afetividade seja trabalhada e possa superar a liquidez desta sociedade.

Neste contexto, o indivíduo aprende o conhecimento por meio da interação com outros sujeitos e objetos existentes no seu ambiente sócio-histórico, de modo que "à medida que as crianças se desenvolvem afetivamente, mudanças paralelas podem ser observadas em seus julgamentos morais [...] (WADSWORTH, 1997 p.74)".

Para o autor Vasconcellos (p.48, 1993), "[...] a mobilização é o momento de solicitar a visão/ concepção que os alunos têm a respeito do objeto (senso comum, "síncrese")". Depois que o professor relacionou o conteúdo com a realidade do acadêmico, é necessário fazer um levantamento prévio do conhecimento da classe sobre o conteúdo que será ministrado, o autor Vasconcellos (1993, p.48) diz que "conhecer a realidade dos educando implica em fazer um mapeamento, um levantamento das representações do conhecimento dos alunos sobre o tema de estudo". Por exemplo, o professor pode fazer o levantamento prévio por meio de conversas abertas, debates, questionários, dinâmicas, jogos entre outras possibilidades, de modo que os discursos preconceituosos possam ser desconstruídos com as intervenções dos docentes, visto que "[...] nos tornamos capazes de comparar, de valorar, de intervir, de escolher, de decidir, de romper, por tudo isso nos fazemos seres éticos" (FREIRE, 2006, p.33).

Em seguida, deve-se iniciar a próxima etapa que é problematização, para o professor Gasparin (p.33, 2012), "é um elemento-chave na transição entre a prática e a teoria, isto é, entre o fazer cotidiano e a cultura elaborada. É o momento que se inicia o trabalho com o conteúdo sistematizado". O professor explorará de modo didático todos os aspectos do conteúdo, com o intuito de que o aluno alcance a consciência da realidade e passe a enxergá-la como um todo, cheia de inter-relações e de interações com a sua vida e com a sociedade.

A finalidade da problematização é eleger as principais interrogações levantadas na prática social e questionar os conteúdos escolares, através de um diálogo entre os alunos e os professores. Por isso, o docente precisa saber da importância do diálogo, visto que "o sujeito que se abre ao mundo e aos outros inaugura com seu gesto a relação dialógica em que se confirma como inquietação e curiosidade, como inconclusão em permanente movimento na História" (FREIRE, 2006, p.136). Sendo que "o mundo encurta, o tempo dilui: o ontem vira agora; o amanhã já está feito. Tudo muito rápido. Debater o que se diz e o que se mostra e como se mostra na televisão me parece algo cada vez mais importante" (FREIRE, 2006, p.139).

O terceiro passo é a instrumentalização, onde o docente apresentará de modo sistematizado o conteúdo. Neste momento, o professor ensina o novo conteúdo, o aluno deve apreender a realizar conexões e ligações entre esses e os já adquiridos por suas experiências sociais, ele deve decodificar as informações. Assim, os conhecimentos prévios dos alunos são utilizados como alicerce para a construção de uma nova aprendizagem, pois, a transformação do 
novo conteúdo acontecerá no momento em que os acadêmicos conseguirem de modo autônomo recriá-los e fazer reflexões sobre esses.

Para o pesquisador Gasparin (2012, p. 51), “a instrumentalização é o caminho pelo qual o conteúdo sistematizado é posto à disposição dos alunos para que o assimilem e o recriem e, ao incorporá-lo, transformem-no em instrumento de construção pessoal e profissional". Assim, é essencial que os problemas sociais que foram levantados na primeira fase, a da prática social, sejam retomados e relacionados com os novos conhecimentos teóricos e práticos que os alunos têm construído.

É necessário também que o docente estimule a criticidade, pois para o pesquisador Freire (2006, p.32) a "[...] promoção da ingenuidade para a criticidade não se dá automaticamente [...]". Estimular a criticidade do aluno é fundamental, talvez uma das ações mais importantes, pois, "a aquisição da informação, dos dados, dependerá cada vez menos do professor. As tecnologias podem trazer, hoje, dados, imagens, resumos de forma rápida e atraente" (MORAN, 2012, p.30).

A outra fase é a catarse, que tem como atividade essencial a síntese, neste momento os alunos devem ser estimulados a compararem intelectualmente os seus próprios conhecimentos, os quais foram construídos ao longo da vida, com os conhecimentos científicos, apresentados pelo professor. O docente tem como desafio possibilitar aos alunos a incorporação desses novos conhecimentos:

Em virtude disso, os educando, com auxílio e orientação do professor, apropriam-se do conhecimento socialmente produzido e sistematizado para enfrentar e responder aos problemas levantados. Dentro dessa perspectiva, não mais de adquire o conteúdo por si mesmo; a apropriação dos conhecimentos ocorre no intuito de equacionar e/ou resolver, ainda que teoricamente, as questões sociais que desafiam o professor, os alunos e a sociedade (GASPARIN, 2012, p.51).

Para a pesquisadora Mateus (2014, p. 97), "nesta fase, o aluno manifesta tudo que aprendeu, assimilou e produziu. A catarse é a síntese de todas as etapas do processo de aprendizagem pelo qual ele passou até apropriar-se do novo conhecimento". Nesta fase, também ocorre à avaliação, a qual não deve ser vista como uma simples prova, ou teste, mas, como uma expressão de todas as etapas passadas para a construção de determinado conhecimento científico. Portanto, a avaliação não acontecerá somente nesta fase e sim durante todo o processo de ensino.

A catarse é a demonstração teórica do ponto de chegada, do nível superior que o aluno atingiu. Expressa a conclusão do processo pedagógico conduzido de forma coletiva para a apropriação individual e subjetiva do conhecimento. É o momento do encontro e da integração mais clara e consciente da teoria com a prática na nova totalidade. Os conteúdos tornam-se verdadeiramente significativos porque passam a fazer parte integrante e consciente do sistema científico, cultural e social de conhecimentos. Os educandos generalizam o aprendido, integrando-o em um todo sistemático, tanto em sua dimensão próximo-vivencial quanto em sua dimensão remota, universal (GASPARIN, 2012, p. 127).

Neste momento espera-se que o acadêmico tenha desenvolvido a habilidade de "[...] explicar suas crenças, a avaliar suas evidências e justificativas e a julgar argumentos para atingir o objetivo máximo de crescimento pessoal, independência e pensamento crítico" (AQUINO, 2007, p.25), visto que a sociedade liquida deixou de questionar os eventos sociais, políticos, econômicos, as relações interpessoais, sendo superficial e individual. Tornou-se "[...] um tipo de sociedade que 
não mais reconhece qualquer alternativa para si mesma e, portanto, sente-se absolvida do dever de examinar, demonstrar, justificar (e que dirá provar) a validade de suas suposições tácitas e declaradas" (BAUMAN, 2001, p.30), portanto, a ação social do docente de estimular a criatividade, é fundamental para superar liquidez deste momento histórico.

Para Gasparin (2012), as matérias ensinadas nas escolas são produtos sociais e históricos, portanto, é essencial que os alunos conheçam o motivo que determinado conteúdo surgiu e como ele serve ainda hoje para a continuidade da nossa cultura. A prática social final é o momento em que o professor e o aluno se transformam, é neste momento em que ambos passam de uma fase de menor compreensão científica para outra de maior conhecimento. É quando ocorre uma mudança de conduta, ou seja, quando os acadêmicos compreendem de um modo mais amplo a realidade, assim, desenvolve análise mais crítica das ideias e dos fatos sociais, de modo que eles possam se emancipar, já que segundo Bauman (2001), A finalidade da educação, nesse caso, seria questionar o impacto que as experiências do dia-a-dia provocam no individuo e na sociedade, além de saber enfrentá-las e por fim desafiar as pressões que surgem do ambiente social (BAUMAN, 2009).

\section{CONCLUSÃO}

Os docentes têm um desafio importante, o de metodologicamente estimular a criticidade nos alunos, de modo que estes consigam questionar os eventos sociais, políticos, econômicos, as relações interpessoais, superando a superficialidade e a individualidade. Assim, o professor tem que a função social de criar formas para tentar superar a liquidez desta sociedade, de modo que um dia os acadêmicos consigam criticar esta sociedade.

Por tanto, a pedagogia Histórico-Crítica, pode ser uma ferramenta para auxiliá-los neste processo, já que sua metodologia permite que o professor conheça a vivência de seus alunos, além dos muros das escolas, possibilitando uma tomada de consciência de ambas às partes. Por meio de um dialogo aberto entre o docente e o discente é possível desenvolver uma consciência crítica sobre a realidade social, a busca pelos conhecimentos científicos e possíveis soluções para a superação desta sociedade liquefeita.

\section{REFERÊNCIAS}

ALBUQUERQUE, R. A. L. DAL, J. L. G. V. Comunicação Empresarial e Negociação. Maringá: Uicesumar - PR, 2014.

ALMEIDA, Felipe Quintão; GOMES, Ivan Marcelo; BRACHT, Valter. Bauman e educação. Belo Horizonte: Autêntica, 2009.

AQUINO, C T E de. Como aprender: andragogia e as habilidades de aprendizagem. São Paulo: Pearson, 2007.

BAUMAN, Z. Modernidade líquida. Rio de Janeiro: Jorge Zahar, 2001.

BAUMAN, Zygmunt. Capitalismo parasitário. Rio de Janeiro: Jorge Zahar: 2010.

BAUMAN, Zygmunt. A sociedade líquida: entrevistado por Maria Lúcia Garcia Palhares-Burke. São Paulo: Folha de São Paulo, 2003. Disponível em: <http:// www.prefeitura.sp.gov.br/cidade/secretarias/upload/chamadas/4_Encontro_ Entrevista_A_Sociedade_Liquida_1263224949.pdf>. Acesso em: Out. 2017. 
. Bauman sobre Bauman. Rio de Janeiro: Zahar, 2011.

BERTONCELLO, L. (Org.) Pós Graduação em EAD. Novas Tecnologias de Informação e Comunicação na Educação Contemporânea. Maringá: CESUMAR: Núcleo de Educação a Distância, 2011.

DOWBOR, L. A formação do terceiro mundo. 3. ed. São Paulo: Brasiliense, 1996.

FREIRE, P. Pedagogia da autonomia: saberes necessários à prática educativa. 34. ed. São Paulo: Paz e Terra, 2006.

FREIRE, Paulo. Pedagogia da autonomia: saberes necessários à prática educativa. 34. ed. São Paulo: Paz e Terra, 2006.

GASPARIN, J. L. Uma Didática para a Pedagogia Histórico-Crítica. 3.ed. Campinas, SP: Autores Associados, 2012.

LIBÂNEO, J. C. Didática. 2. ed. São Paulo: Cortez, 2012.

MAFRA, D. Técnicas de comunicação. Curitiba: Senac/ Diret, 2009.

MATEUS, I. B. B. Didática. Maringá: Uicesumar - PR, 2014.

MATOS, G. G. Comunicação Empresarial sem complicação. 2 ed. São Paulo: Manoele, 2009.

MINAYO, M. C. DE S. Pesquisa Social: teoria, método e criatividade. Petrópolis, RJ: Vozes, 2011.

MORAN, J M. Novas tecnologias e mediação pedagógica. 19. ed. Campinas, SP: Papirus, 2012.

PATRONI, R. et al. (Org.) Pedagogia. Novas Tecnologias na Educação. Maringá: CESUMAR: Núcleo de Educação a Distância, 2009.

REGO, T. C. Vygotsky: uma perspectiva histórico-cultural da educação. Petrópolis, Rio de Janeiro: Vozes, 1995.

REIS, L. G. Produção de monografia: da teoria à prática. Brasília: Senac - DF, 2008.

Rio de Janeiro: Vozes, 1995.

VASCONCELLOS, C D S. Construção do conhecimento em sala de aula. São Paulo: Salesiana Dom Bosco, 1993.

WADSWORTH, B J. Inteligência e Afetividade da Criança na Teoria de Piaget. 5 ed. São Paulo: Pioneira, 1997. 